\title{
THE EFFECT OF WELDING HEAT INPUT AND WELDING SPEED ON MICROSTRUCTURE OF CHROMIUM - MANGANESE STAINLESS STEEL GAS TUNGSTEN ARC WELDED PLATES
}

\author{
Sudhakaran . $\mathbf{R}^{1}$, Siva Sakthivel P. $\mathbf{S}^{2}$, Nagaraja $\mathbf{S}^{3}$ \\ ${ }^{1}$ Professor, Department of Mechanical Engineering, SNS College of Engineering, Coimbatore, India \\ ${ }^{2}$ Assistant Professor, Department of Mechanical Engineering, SASTRA University, Thanjavur, Tamil Nadu, India \\ ${ }^{3}$ Assistant Professor, Department of Mechanical Engineering, SNS College of Engineering, Coimbatore, India
}

\begin{abstract}
The quality of any weld joint is highly influenced by the microstructure of the weldment. The quality of the weldment gets deteriorated due to metallurgical changes such as micro-segregation, precipitation of secondary phases, presence of porosities, grain growth in the heat affected zone and loss of material by vaporization. This paper presents study on the effect of welding process parameters such as welding current, welding speed, on the metallography of AISI202 grade chromium manganese stainless steel Gas Tungsten Arc Welded Plates. Experiments were conducted using bead on plate method keeping one parameter at the minimum and maximum levels and keeping the other parameters constant. The metallographic study concentrated on the grain structure, presence of carbides and formation of ferrite, austenite and martensite in the weldment. The obtained results help in selecting quickly the required process parameters to achieve the desired weld quality.
\end{abstract}

Keywords: Gas Tungsten Arc Welding, Stainless Steel, Process Parameters, Grain Structure,

\section{INTRODUCTION}

Gas Tungsten Arc Welding (GTAW) is an arc welding process that produces coalescence of metals by heating them with an arc between a non consumable electrode and base metal. It is commonly used for welding hard to weld metals, such as aluminium, stainless steel, magnesium and titanium [1]. With the increased use of mechanized welding, the selection of welding process parameters and welding procedure must be more specific to ensure that good quality weld is obtained with minimum cost and high repeatability [2]. GTAW quality is strongly characterized by the welding process parameters. This is because the bead geometry plays an important role in determining the microstructure of the weld and hence the mechanical properties of the weld [3]. Hence the input welding variables which influence the properties must therefore be properly selected to obtain a high quality joint. Stainless steels may suffer from various forms of metallurgical changes when exposed to critical temperatures. In welding the region of heat affected zone often experiences temperatures that are sufficient to promote microstructural changes. The precipitation of chromium nitrides, carbides and carbonitrides may occur under various conditions depending on the stainless steel grade. The AISI 200 series steels are nitrogen strengthened and are commonly referred as nitronic steels. This grade contains high levels of carbon, manganese and nitrogen and is used in specialty applications such as where galling resistance is required. They also have low nickel content than 300 series to balance high carbon and nitrogen levels. The AISI202 grade stainless steel is formulated and thermo mechanically processed such that the microstructure is primarily austenite. Depending on the balance of ferrite promoting to austenite promoting elements the cast microstructure will be either fully austenite or a mixture of austenite and ferrite. The microstructure of fusion zone of 202 grade stainless steel is dependent both on the solidification behaviour and subsequent solid state transformations after welding [4]. During GTAW process, the formations of coarse grains and inter granular chromium rich carbides along the grain boundaries in the heat affected zone deteriorates the mechanical properties.

Subodh Kumar and Shahi [5] studied the effect of heat input on the microstructure of GTA welded AISI304 grade stainless steel joints. They used three heat input combinations for their study. They are designated as low heat $(2.56 \mathrm{~kJ} / \mathrm{mm})$, medium heat $(2.784 \mathrm{~kJ} / \mathrm{mm})$, and high heat $(3.017 \mathrm{~kJ} / \mathrm{mm})$. From their study, they have found that significant grain coarsening was observed in the HAZ for all the joints. They have also found that the extent of grain coarsening in the HAZ increased with the increase in heat input and average dendrite length and interdendritic spacing in the weld zone also increases with the increase in heat input. Huaibei et al [6] studied the microstructure of low carbon $12 \%$ chromium stainless steel in high temperature heat affected zone. The major problems associated with low carbon $12 \% \mathrm{Cr}$ stainless steel during 
welding are coarsening and embrittlement. In their study, they have investigated the microstructures in high temperature heat affected zone with different chemical compositions and heat inputs through thermal simulation tests. From their study they have inferred that the heat input influences the microstructure of steel in high temperature heat affected zone and the grain size grows up with the increase in heat input.

Cleiton et al [7] evaluated the heat affected zone microstructure of AISI444 ferritic stainless steel welded plates. From their study they have inferred that weld thermal cycle caused micro phase precipitation in the HAZ of the ferritic stainless steel. They have also observed needle like laves phase precipitation in the heat affected zone and near the partially melted zone. Tsann-Shyichern et al [8] investigated the effects of the specific fluxes like $\mathrm{TiO} 2, \mathrm{SiO} 2, \mathrm{MnO} 2$, $\mathrm{MoO} 3$ and $\mathrm{Cr} 2 \mathrm{O} 3$ on surface appearance, weld morphology, angular distortion, mechanical properties and micro structures of $6 \mathrm{~mm}$ thick duplex stainless steel plates. The results of their study indicate that using activated flux increases the mechanical strength of the joint. The microstructure of the flux coated specimen revealed that there is an increase in delta ferrite content from $45.9 \%$ to $63.4 \%$. Jiang et al [9] studied the microstructure characteristics in TIG welded joint of $\mathrm{Mo}-\mathrm{Cu}$ composite and 18-8 stainless steel. They used $\mathrm{Cr}-\mathrm{Ni}$ fillet wires for their experiments. They analyzed the microstructure element distribution, phase constituents and micro hardness of the joint. The results of their study indicate that austenite and ferrite structures were observed in the fusion zone near 18-8 stainless steel. They have also found that copper agglomeration regions were formed in $\mathrm{Mo}-\mathrm{Cu}$ composite heat affected zone during welding.

Dennis et al [10] characterized the distribution of residual stress and the microstructure changes in FCAW of $13 \% \mathrm{Cr}$ $4 \% \mathrm{Ni}$ Martensitic stainless steel. From their study, they have inferred that the microstructure of the weld consists of martensite and little ferrite that did not transform to austenite on cooling. They also found that a small amount of retained austenite is found in the welded joint which is due to the heat treatment of base metal before welding. Kacar and Acarer [11] studied the microstructure -property relationship in explosively welded duplex stainless steel and vessel steel. In their work they have cladded duplex stainless steel 2205 grade and vessel steel (DIN-P355GH) using explosive welding. They have inferred that the cladded materials have proved that mechanical and corrosion properties of low carbon steels can be increased by explosive cladding with duplex stainless steel. Shah Hosseini et al [12] investigated the microstructure and mechanical properties of Inconel 617/310 austenitic stainless steel dissimilar welds. From the microstructural observations, they showed that there was no cracking in the weldments. The mechanical properties of Inconel 617 filler material are superior to that of the other filler materials. Tae Jun Park et al [13] studied the effect of Al-Si coating layer on the microstructures of ferritic stainless steel and 409L using GTA welding process. They have found from their investigations that the grain size of both materials was the largest in the fusion zone and decreased from near the heat affected zone to the base metal. Lakshminarayanan et al [14] studied the effect of welding processes on microstructure of AISI409M ferritic stainless steel joints fabricated by duplex stainless steel filler metal. The welding processes used for their study are SMAW, GMAW and GTAW. They used rolled plates of $4 \mathrm{~mm}$ thickness as base material for preparing single pass butt welded joints. They have compared the mechanical properties of different welding processes. From their investigation they have found that GTA welded joints of ferritic stainless steel have superior tensile and impact properties compared with SMAW and GMAW joints. This is mainly attributed to the presence of finer grains in fusion zone and HAZ.

From the literature, it can be inferred that There were many works carried out to study the microstructure of different grades of stainless steel for various welding processes but no work has been reported for 200 series stainless steel especially 202 grade for GTAW process. AISI 202 grade chromium manganese stainless steel has nitrogen in it, which is a very effective strengthening addition, and hence is generally harder and stronger than 300 series. It has 30\% higher yield strength than 304 grade stainless steel. Hence in most applications like manufacturing of food processing equipment, kitchen equipment, propeller shafts for motor boats and medical instruments it can be used as an alternate for 304 grade stainless steel [15]. The rise in popularity of these grades is linked to world Nickel price volatility and advances in steel production technology. In countries like India which has no indigenous supply of Nickel, there is a potential for growth of these grades. But before considering these grades for any application detailed investigation has to be carried out regarding its suitability, since there are certain instances where 200 series grades have failed due to corrosion and other problems. Therefore, it becomes imperative to understand the microstructure of these grades before considering it for any application. Hence in the present work AISI 202 grade chromium manganese stainless steel is chosen with the following chemical composition

Table 1 Chemical Composition of Stainless Steel 202 Grade

\begin{tabular}{|l|l|l|l|l|l|l|l|l|l|l|}
\hline AISI Designation & UNS Designation & \% C & \% Mn & \%Si & \% Cr & \% Ni & \%P & \% & \% & \% Fe \\
\hline 202 & S20200 & 0.15 & 9.25 & 0.49 & 17.1 & 4.1 & 0.06 & 0.03 & 0.25 & 70.01 \\
\hline
\end{tabular}


A detailed microscopic study has been made to study the effect of welding process parameters namely; welding current and welding speed on the fusion zone, heat affected zone and base metal. The study on the structure of the specimen's revealed the influence of process parameters on grain structure, grain coarsening in the heat affected zone and weld metal. It also gave an idea about formation of martensite and ferrite veins in the weld metal.

\section{EXPERIMENTAL PROCEDURE}

The experiments were conducted based on bead on plate method using Lincoln V 350 PRO electric digital welding machine. A servo motor driven manipulator was used to maintain uniform welding speed. The main experimental set up used consisted of a traveling carriage with a table for supporting specimens. A power source was kept ready. A welding gun was held stationary in a frame above the table and was provided with an attachment for setting the required nozzle to plate distance and welding gun angle respectively. The nozzle to plate distance was kept constant at $2.5 \mathrm{~mm}$ throughout the experimentation process. A high frequency attachment was used to generate the arc at this distance. Test plate of sizes $(100 \mathrm{~mm} \times 35 \mathrm{~mm} \times 5 \mathrm{~mm}$ ), were cut from 202 grade stainless steel plates and one surface was cleaned to remove oxide scale and dirt before welding.

Argon gas flow rate was varied for each experiment as per the requirements. The discharge was controlled using the flow meter in liters per minute. The experimental set up used for conducting the experiments is shown in Fig 1 and the welded specimens were shown in Fig 2.

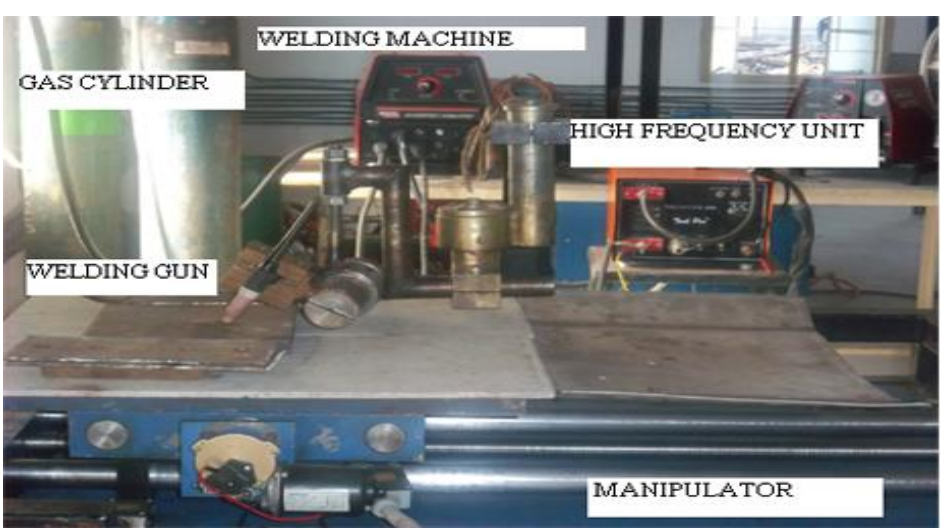

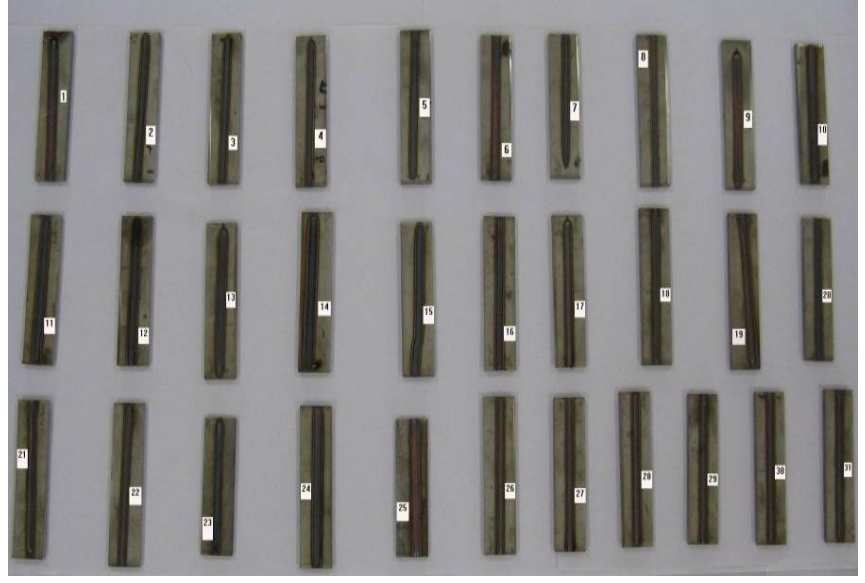

Fig 2 Welded Specimens

\section{RESEARCH METHODOLOGY}

The working ranges of welding current and welding speed were fixed by conducting trial runs. The trial experiments are conducted separately to identify the range of parameters. The following methodology was adopted to indentify the ranges welding current and welding speed

The upper limit and lower limit of each process variable has to be first identified. This was done by conducting trial runs, for example to identify the lower and upper limit of welding current, the trial runs were conducted for varying values of welding current from 50 amps to 120 amps.

When conducting these trials, the value of welding speed is set at a particular value i.e. $\mathrm{V}$ at $100 \mathrm{~mm} / \mathrm{min}$. Then the bead was inspected to identify any defects and for smooth appearance. Then based on the quality of the bead, the levels were fixed. From the trial runs 70 amps and 110 amps were fixed as lower and upper limits for welding current. The same procedure was adopted for determining the limits for welding speed.

The selected process parameters with their limits and notations are given in Table 2. The experiments were conducted when one process parameter is maintained at the minimum and maximum levels where as the values of the other variables are set at their middle level.

Fig 1 Experimental Set Up

Table 2 Welding Parameters and their Levels

\begin{tabular}{|l|l|l|l|l|}
\hline Parameter & Unit \& Notation & \multicolumn{3}{|l|}{ Range of Process Parameters } \\
\cline { 3 - 5 } & & Lower Level & Middle Level & Higher Level \\
\hline Welding Current & Amps (I) & 70 & 90 & 110 \\
\hline Welding Speed & $\mathrm{mm} / \mathrm{min}(\mathrm{V})$ & 170 & 190 & 210 \\
\hline
\end{tabular}




\section{SPECIMEN PREPARATION}

The specimens were prepared using routine metallographic methods [16]. The specimen extraction plays a vital role in metallographic study. The processes were carried out in metallographic study.

- Sectioning

- Mounting

- Mechanical grinding and polishing

- $\quad$ Etching

- Examination of the specimens

\subsection{Sectioning}

It is the removal of a conveniently sized and representative specimen from a larger piece. It is the first major operation in the preparation of metallographic specimens. Metallurgical sectioning may also be used to prepare specimens for tests other than microstructure evaluation. Metallurgical sectioning is important and critical when preparing specimens for physical or microscopic analysis. Metallography by its nature is a destructive test where by some material is lost in the preparation process. Sectioning results in loss in material when it is performed along its width. Grinding and polishing also results in further losses. Therefore extreme care should be taken in selecting test locations.

In this work abrasive cutting was used for sectioning of samples from the welded specimens. It is the sectioning of material using a relatively thin rotating disk composed of abrasive particles supported by a suitable medium. The thousands of particles contacting the material in rapid succession and at very high speeds section the material. In this work, Al2O3 wheels with fine grains are used for cutting the specimens. The wheels with grit size of 120 were used for sectioning of the specimens.

\subsection{Mounting of the Specimens}

After a metallographic specimen is cut to an appropriate size, mounting of the specimen is necessary for subsequent handling and metallographic polishing. The mounting of the specimens are done by encapsulating the specimen in a polymeric material. Prior to mounting, the specimens are first cleaned to remove solid dirt, grease or other debris. The cleaning process is done manually.

\subsection{Mechanical Grinding and Polishing}

Investigations of the structures of metals are generally carried out on sections that have been cut from a bulk specimen. The metallographic investigation of the specimen involves the reflection of some form of radiation from the section surface. An image of the surface is formed from the reflected radiation that allows variations in crystal structure or composition over the surface to be discerned.
To prepare the cut surface suitably for metallographic examination the surface should be machined and polished to increase its fineness. After sectioning the specimens, grinding is done at high surface speeds which results in significant heating of surface layers of the specimens. This is followed by abrasion at low surface speeds.

Both grinding and abrasion processes increase the finenesses of the specimen surface. The grinding and abrasion is followed by polishing using a cloth. The objective is to produce a bright mirror like reflecting surface commonly referred to as a polished surface.

\subsection{Etching of the Specimens}

A polished specimen does not exhibit its microstructure because light is uniformly reflected. The eye cannot discern small differences in reflectivity; hence image contrast must be produced. To produce image contrast, etching is essentially required. Etching is used in metallography primarily to reveal the microstructure of the specimen under the optical microscope [17]. There are number of etching methods available like optical, electro chemical and physical etching. In this work the etching of specimens were carried out using micro etching method. Nital solution $(100 \mathrm{ml}$ ethanol and $5 \mathrm{ml}$ nitric acid) was used as an etchant for etching the specimens.

\subsection{Examination of the Specimens}

The light microscope is most widely used tool for the study of microstructure in spite of availability of sophisticated electron metallographic instruments. Most micro structures can be observed with the light microscope and identified based on their characteristics. In this work (Make: Metzer, Model: MBE-6080BX) was used for the microscopic study of the specimens. The specimens prepared for metallographic study is shown in Figure 3

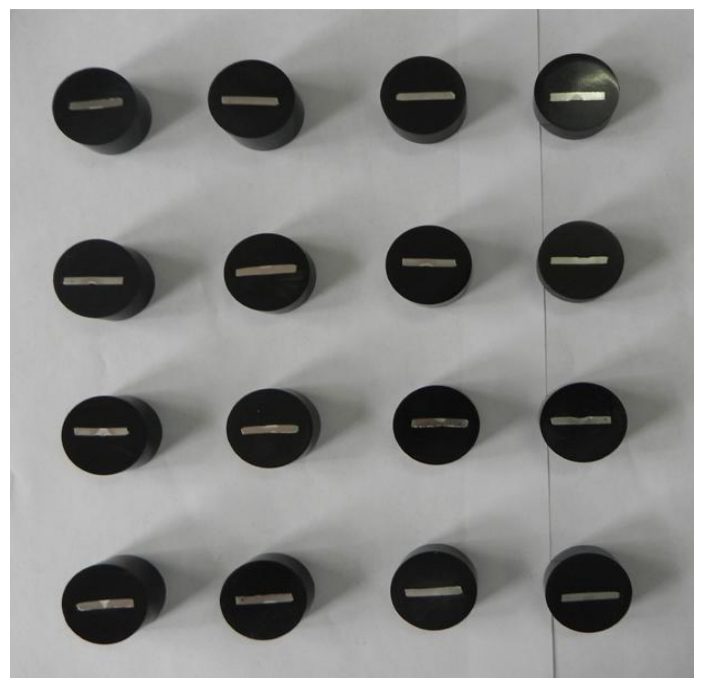

Fig 3 Specimens Prepared for Metalloprphic Study 


\section{METALLURGY OF FUSION WELDS}

A weldment formed by fusion welding results in the formation of monolithic structure but a joint varies in metallurgical structure from point to point with variation in mechanical properties. This is because welding results in the high temperature encountered in the weld pool to the ambient along the transverse direction to the weld axis. The extent of the zone affected depends on the welding process parameters and the physical properties like the melting point, thermal diffusivity of the work material [18]. The weldment can be divided into three distinct zones 1) weld metal zone 2) heat affected zone and 3) unaffected zone base metal zone. In between the weld metal zone and heat affected zone lies the fusion zone which is the volume of the parent metal actually melted to form a part of the weld metal zone or the weld bead. The weld metal zone constitutes the weld bead and is a cast structure. The heat affected zone is the heat treated zone portion of the weldment. The unaffected base metal is the original work material plus a small zone which has been heated to about $650^{\circ} \mathrm{C}$ and hence has undergone a slight change in its grain size and thus mechanical properties [19]. Depending on the material composition and welding process parameters different microstructures are formed from the different zones of a weldment [20]. It is often intended to achieve fine - grained structure in weld bead because this structure leads to

1) Reduced susceptibility of the weld metal to solidification cracking during welding.

2) It helps to improve the mechanical properties.

Fine grain structure in weld metal can be developed by the processes of inoculation, arc oscillation, arc pulsation and weld pool stirring. The following microstructures are encountered in weld metal and heat affected zone of steel welds

1) Delta Ferrite, 2) Austenite, 3) Grain Boundary Ferrite 4) Martensite 5) Retained Austenite

\section{RESULTS AND DISCUSSION}

The metallographic studies were carried out on the welded specimens obtained when the process parameters are maintained at their maximum and minimum levels. Figure 4 to Figure 8 shows the microstructure of the base metal, weld zone and fusion zone of the welded specimens.

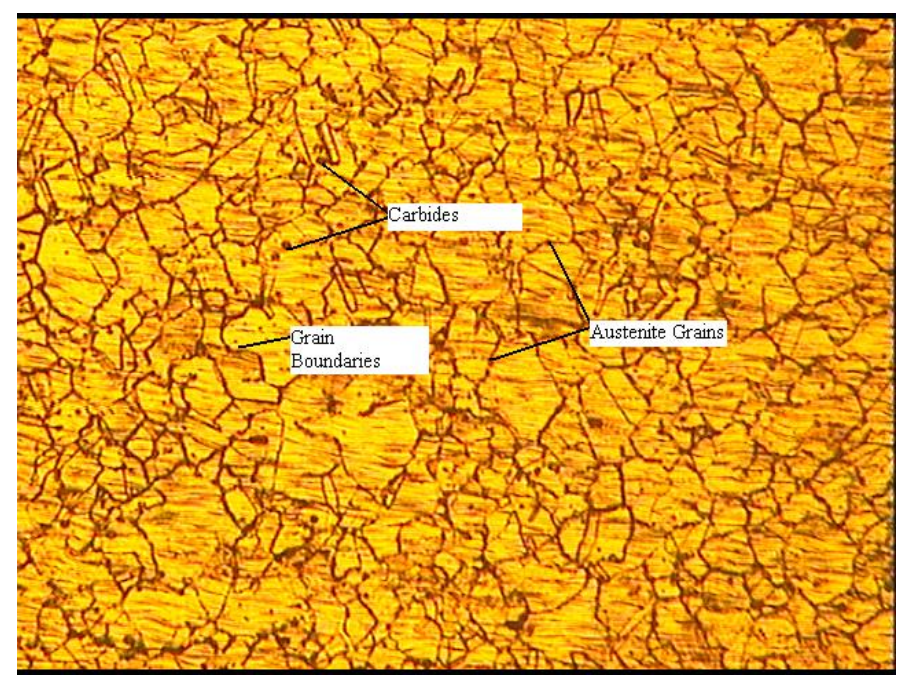

Fig 4 Microstructure of the Base Metal

Figure 4 shows the micro graph of the base metal of AISI202 grade stainless steel plate. The AISI202 stainless steel base metal consists of equiaxed austenite grains. There are some small amounts of dispersed carbide particles at boundaries of austenite grains. Hence the base metal has fully austenitic structure with small amount of dispersed carbide particles at the grain boundaries.

\subsection{Effect of Heat Input on the Microstructure of the}

\section{Weldment}

The welding current is directly proportional to heat input. As the current increases the heat increases. When the welding current is at 110 amps a maximum heat input of $7.7 \mathrm{KJ} / \mathrm{mm}$ is received by the specimen and the minimum heat input of 4.9 $\mathrm{KJ} / \mathrm{mm}$ received by the specimen at 70 amps.

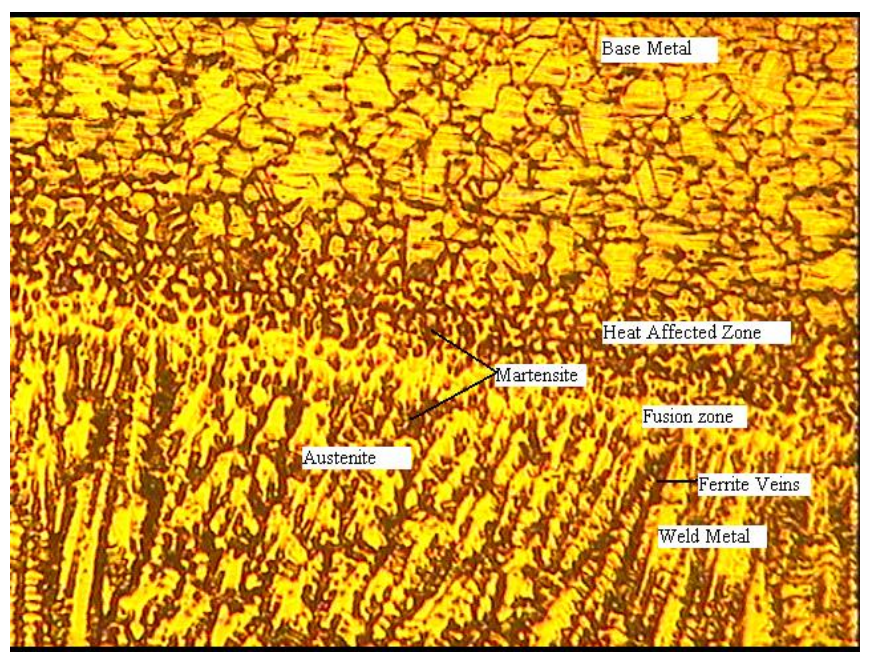

Fig 5 Microstructure of Weld Metal, HAZ and Base Metal of Specimen with High Heat Input 
Figure 5 shows the micro graph of weld metal, heat affected zone and base metal of specimen welded using high heat input of $7.7 \mathrm{~kJ} / \mathrm{mm}$ and other parameters namely: welding speed, welding gun angle and shielding gas flow rate are maintained at $190 \mathrm{~mm} / \mathrm{min}, 70^{\circ}$ and 15 liters $/ \mathrm{min}$. The base metal has equiaxed grains of austenite with presence of small carbide particles at the grain boundaries. Significant microstructural changes can be observed in the heat affected zone due to polymorphous transformations. Due to high heat input, the heat rate is high and the retention time is short at high temperature. This results in formation of non-homogenous austenite during welding. Coarse grain structure is observed in the heat affected zone near the fusion boundary. This is because at high heat input, cooling rate is slow which provides ample time for dendrites to grow farther into the fusion zone. Hence the extent of grain coarsening in the heat affected zone increases for high heat input. The presence of ferrite veins along grain boundaries can be observed in the weld metal. This is because during cooling of the weldment, on reaching the $\gamma-\alpha$ transformation stage, one of the secondary transformations is ferrite veins. The ferrite veins are considered detrimental to toughness, because of its coarse grain structure. A significant amount of needle like martensite is also found in the austenite matrix due to cooling of steel in austenite condition.

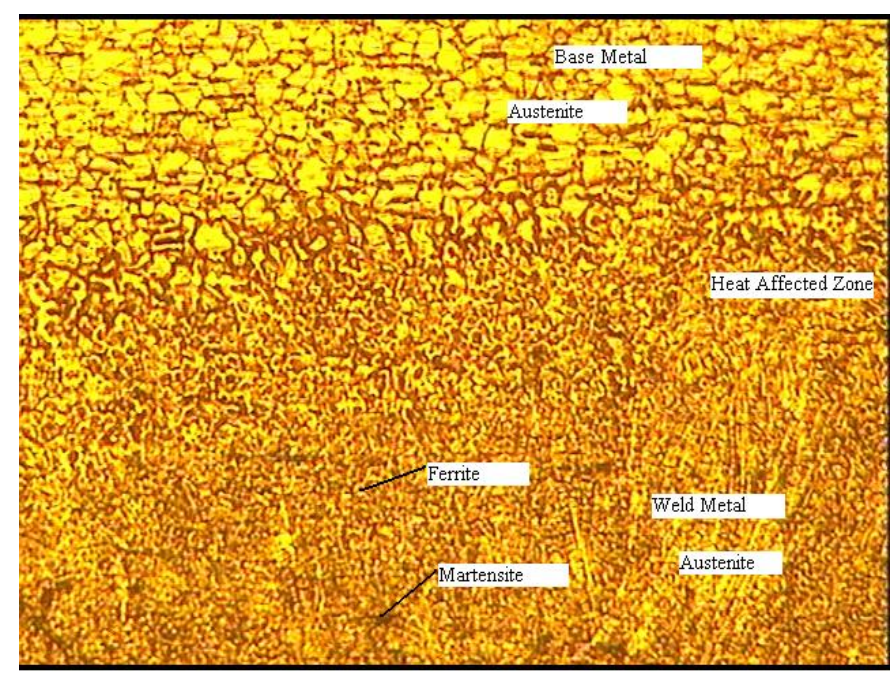

Fig 6 Microstructure of Weld Metal, HAZ and Base Metal of Specimen with Low Heat Input

Figure 6 shows the micrograph of weld metal, heat affected zone and base metal of specimen welded using low heat input of $4.9 \mathrm{~kJ} / \mathrm{mm}$ and other parameters namely: welding speed, welding gun angle and shielding gas flow rate are maintained at $190 \mathrm{~mm} / \mathrm{min}, 70^{\circ}$ and 15 liters $/ \mathrm{min}$. From the microstructure it can be observed that the base metal has equiaxed grains of austenite with small amount of carbide particles. The heat affected zone has relatively low coarsening of grains compared to the previous microstructure. This is because due to low heat input, cooling rate is relatively higher which results in steep thermal gradients in the weld metal. This allows less time for dendrites to grow. Hence the grain coarsening is low at low heat input. In the weld metal significant portion of austenite is retained. There is an equal proportion of tempered martensite which occurs due to cooling of steel from austenite condition. There is also a small amount of ferrite in the austenite matrix.

\subsection{Effect of Welding Speed on the Microstructure of}

\section{the Weldment}

Figure 7 shows the micro graph of weld metal, heat affected zone and base metal of specimen welded using a welding speed of $170 \mathrm{~mm} / \mathrm{min}$ and other parameters namely: welding current, welding gun angle and shielding gas flow rate are maintained at $90 \mathrm{amps}, 70^{\circ}$ and 15 liters/min.

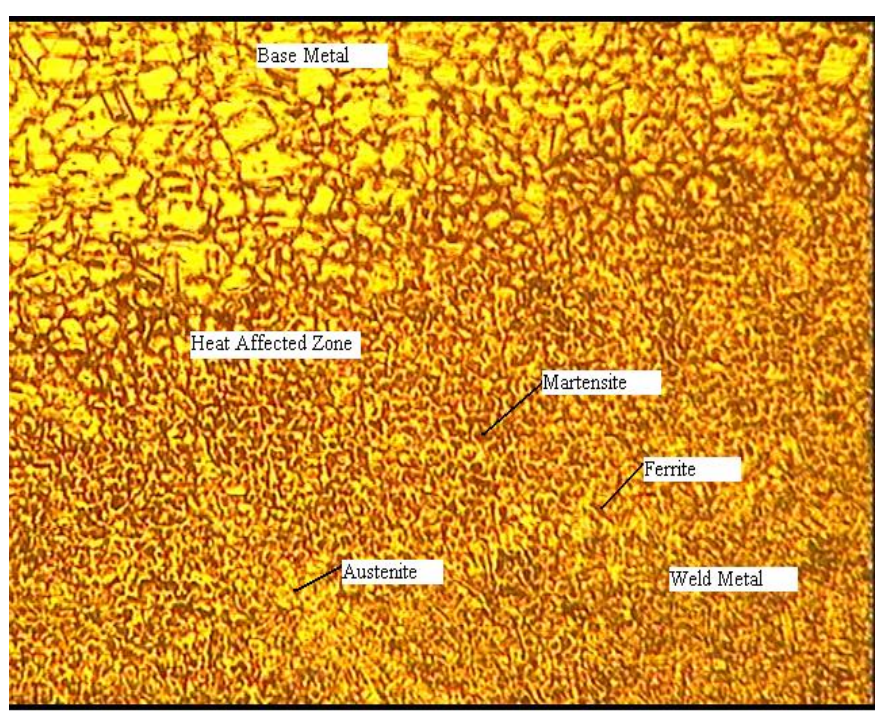

Fig 7 Microstructure of Weld Metal, HAZ and Base Metal of Specimen with Low Welding Speed

The base metal has equiaxed austenite grains similar to that of other specimens. The weld pool tends to be elliptical at low welding speeds. Since the boundary of the trailing portion of the elliptical weld pool is curved the grains are also curved in order to grow perpendicular to the pool boundary. Hence at low welding speeds, columnar grains will curve and grow in the direction of welding. At these welding speeds axial grain growth can be observed in the fusion zone. The axial grains also grow perpendicular to the weld pool boundary. This can be observed in the weld metal. The cooling rate is low at these welding speeds. This gives ample time for dendrites to grow faster into the fusion zone. Hence, it results in the formation of coarse grain structure in the heat affected zone. It can also be observed in the weld metal that there is a significant transformation of austenite into tempered martensite and a meager portion of ferrite in the microstructure. 
Figure 8 shows the micro graph of weld metal, heat affected zone and base metal of specimen welded when the welding speed is at $210 \mathrm{~mm} / \mathrm{min}$ and other parameters namely: welding current, welding gun angle and shielding gas flow rate are maintained at $90 \mathrm{amps}, 70^{\circ}$ and 15 liters $/ \mathrm{min}$. From the figure, it can be inferred that the base metal has equiaxed austenite grains with small amount of carbide particles along the grain boundaries. At higher welding speeds, weld pool takes elongated shape. Since the boundary of trailing portion of the elongated weld pool is straight the grains grow perpendicular to the pool boundary. The columnar grains grow straight towards the weld center line. It can be observed in the heat affected zone that grains are relatively fine when compared with specimen that is maintained at low welding speed. This is because at high welding speed, cooling rate is high. Due to this steep, thermal gradients are established which inturn allow lesser time for the grains to grow. This results in relatively fine grain structure.

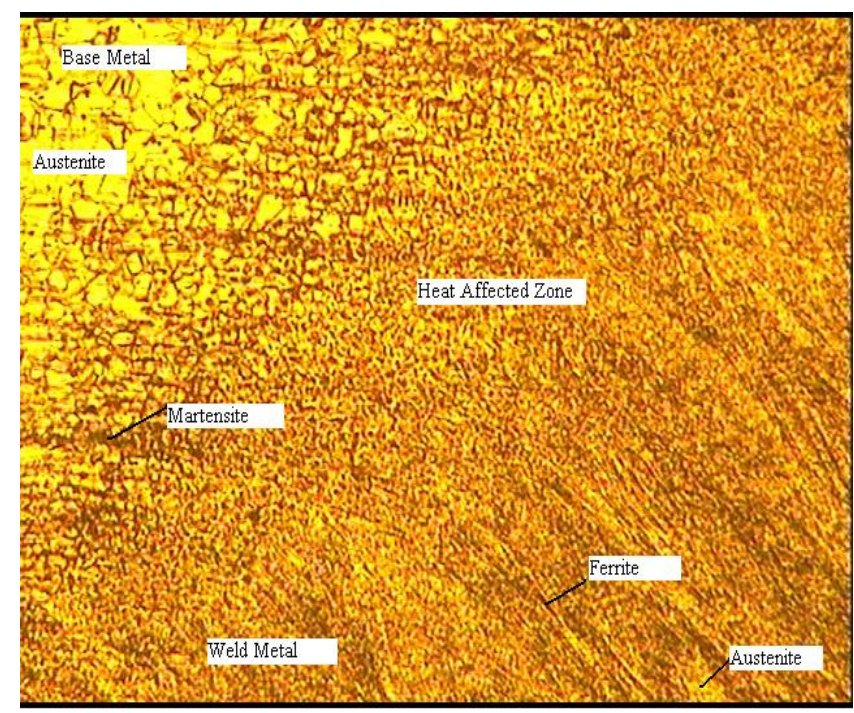

Fig 8 Microstructure of Weld Metal, HAZ and Base Metal of Specimen with Welding Speed at Higher Level

\section{CONCLUSIONS}

The studies on metallography of the welded specimens were carried out to investigate the effect of process parameters like welding current, welding speed, shielding gas flow rate and welding gun angle on the microstructure of AISI202 grade stainless steel GTAW plates.

The following conclusions were arrived at from the investigations.

1. The base metal of AISI202 grade stainless steel has equiaxed grains of austenite with presence of small carbide particles at the grain boundaries

2. Grain coarsening is observed in the heat affected zone due to increase in heat input
3. In the weld metal zone significant amount of austenite is retained along with needle like martensite structure.

4. The presence of ferrite in the form of ferrite veins is also observed in the weld metal zone due to increase in heat input

5. When the heat input is maintained at a lower value of $4.93 \mathrm{~kJ} / \mathrm{mm}$, grain coarsening decreases and fine grains are formed in the heat affected zone and significant portion of austenite is retained along with equal proportion of tempered martensite in the weld metal zone

6. When the welding speed is maintained at a lower level of $170 \mathrm{~mm} / \mathrm{min}$ coarse grain structure is observed in the heat affected zone and there is a significant transformation of austenite into tempered martensite with meager portion of ferrite in the microstructure in the weld metal zone

7. When the welding speed is maintained at a higher level of $210 \mathrm{~mm} / \mathrm{min}$, fine grains are formed in the heat affected zone and major proportions of austenite is retained along with equal proportion of martensite in the weld metal zone. There is also some ferrite veins observed along the grain boundaries in the weld metal zone

\section{REFERENCES}

[1] Kumar A, Sundararajan S (2008) Effect of welding parameters on mechanical properties and optimization of pulsed TIG welding of $\mathrm{Al}-\mathrm{Mg}-\mathrm{Si}$ alloy Int. J Adv Manu Technol doi: 10.1007/s00170-008-1527-8.

[2] Gridharan, P.K and N., Murugan (2008) Optimization of pulsed welding process parameters for the welding of AISI $304 \mathrm{~L}$ stainless steel sheets Int J Adv Manuf Technol DOI 10.1.1007/S00170 - $008-1373-0$.

[3] Cary, H. B (1989) Modern welding technology Prentice Hall Englewood cliffs New Jersey.

[4] Damian J. Kotecki and John C. Lippold (2005) Welding metallurgy and weldability of stainless steels John Wiley and Sons New York.

[5] Subodh Kumar, Shahi. A.S (2011) Effect of heat input on the microstructure and mechanical properties of gas tungsten arc welded AISI304 stainless steel joints Materials and Design 32:3617-3623.

[6] Huaibei Zheng, Xiaoning Ye, Laizhu Jiang, Baosen Wang, Zhenyu Liu and Guodong Wang (2010) Study on microstructure of low carbon $12 \%$ chromium stainless steel in high temperature heat-affected zone Materials and Design 31:4836-4841.

[7] Cleiton C. Silva, Jesualdo P. Farias, Helio C. Miranada, Rodrigo F. Guimardes, John W.A. Menezes and Moises A.M.Neto (2008) Microstructural characterization of the HAZ in AISI 444 ferritic stainless steel welds Materials Characterization 59:528533. 
[8] Tsann-Shyi Chern, Kuang-Tseng and Hsien-Lung Tsai (2011) Study of the characteristics of duplex stainless steel activated tungsten inert gas welds Materials and Design 32:255-263.

[9] Jiang Qinglei, Li Yajiang, Puchkov. U.A, Wang Juan and Xia Chunzhi (2010) Microstructure characteristics in TIG welded joint of Mo-Cu composite and 18-8 stainless steel Int. Journal of Refractory Metals and Hard Materials 28:429-433.

[10] Dennis Thibault, Philippe Bocher and Marc Thomas (2009) Residual stress and microstructure in welds of $13 \% \mathrm{Cr}-4 \% \mathrm{Ni}$ martensitic stainless steel $\mathrm{J}$ Mater Process Technol 209:2195-2202.

[11] Kacar. R and Acarer. M (2003) Microstructureproperty relationship in explosively welded duplex stainless steel-steel Materials Science and Engineering A363:290-296.

[12] Shah Hosseini. H. Shamanian. M and Kermanpur. A (2011) Characterization of microstructures and mechanical properties of Inconel 617/310 stainless steel dissimilar welds, Materials Characterization 62:425-431.

[13] Tae Jun Park, Jong Pan Kong, Sang Ho Uhm, In Su Woo, Jong Sub Lee and Chung Yun Kang (2011) Effect of $\mathrm{Al}-\mathrm{Si}$ coating layer on the penetration and microstructures of ferritic stainless steel 409L GTA welds J Mater Process Technol 211:415-423.

[14] Lakshminarayanan. A.K, Shanmugam. K and Balasubramanian. V (2009) Effect of welding processes on tensile and impact properties, hardness and microstructure of AISI $409 \mathrm{M}$ ferritic stainless joints fabricated by duplex stainless steel filler material, Journal of Iron and Steel Research 16(5): 6672.

[15] International stainless steel forum (ISSF) (2005) New 200 series steels- An opportunity or threat to the image of stainless steel http://worldstainless.org. Accessed on 12 October 2013

[16] Robert W. Messler, JR (1999) Principles of welding John Wiley and Sons New York.

[17] Jun Yan, Ming Gao and Xiaoyan Zeng (2009) Study on microstructure and mechanical properties of 304 stainless steel joints by TIG, laser and laser-TIG hybrid welding Optics and Lasers in Engineering 48: 512-517.

[18] Shaogang Wang, Qihui Ma and Yan Li (2011) Characterization of microstructure, mechanical properties and corrosion resistance of dissimilar welded joint between 2205 duplex stainless steel and $16 \mathrm{MnR}$ Materials and Design 32:831-837.

[19] Yazdipour. A.R, Shafiei. A and Jamshidi Aval.H (2011) An investigation of the microstructure and properties of metal inert gas and friction stir welds in aluminium alloy 5083 Sadhana 36(4):505-514. 